\title{
Artistic Characteristics of Classical Pop Songs in China Hongxing Ren
}

\author{
School of Music, Shaanxi Normal University, Xi'an, 710119, Chin
}

Key words: China, classical pop songs, artistic characteristics

\begin{abstract}
In this paper, the author mainly made an in-depth analysis on artistic characteristics of Chinese pop music. Emphasis was laid on the analysis on artistic characteristics of some classical pop songs. On this basis, the author also analyzed music at the mainland and in Hong Kong and Taiwan respectively. At the same time, the author also made a research on some Chinese classical pop music influenced by foreign pop music, and expected to further promote the development of prosperity of Chinese pop music.
\end{abstract}

With the continuous and rapid development of China's economy and society, pop song, as an artistic form to be loved by the masses, gradually demonstrates richer and richer and more diversified characteristics. With different artistic features, pop songs at the mainland and in Hong Kong and Taiwan captured numerous audiences respectively. In this paper, the author mainly analyzed some classical pop songs since the reform and opening up, and expected to further promote the development of Chinese pop music based on a deep analysis on its artistic characteristics.

\section{Close to Life}

As everyone knows, one of important charms of pop music is its closeness to the real life, so as to avoid being too high to be popular.

With the words of pop songs as an example, many Chinese classical pop songs have beautiful words and fascinating characteristics. Moreover, these classical pop songs are extremely close to the historical background and real life at that time. Generally speaking, the words of pop songs mainly include four forms: narration, emotional expression, depiction of scenery and testimonials. The form of narration plus emotional expression is the most frequently seen and loved by the most audiences. There are many master works for this category of classical pop songs, such as Xiaofang (Li Chunbo), The Half Moon (Liu Huan) and One Thousand Sad Reasons (Jacky Cheung, Hong Kong).

With Xiaofang as an example, this pop song is loved by the masses because of its beautiful melody and readability as well as its vivid expression of the words. The words of Xiaofang in the verse: there is a girl called Xiaofang in the village. She is kind-hearted as well as beautiful, with a pair of big eyes and long braids. At the night before going back to the city, you and I came to the riverside. My tears fell down with the small river. Several simple sentences expressed the image of lovers unwilling to leave each other. Moreover, it is quite accurate and vivid in terms of the description on figures and scenes, making the audiences to naturally generate the sense of picture. It's worth noting that the reasons for Xiaofang to become a classical pop song in the 1990s at the mainland are graceful music, moving words and the historical background. With the comprehensive bringing order out of chaos after the Third Plenary Session of the 11th Central Committee of the CCP, a group of educated youths in the 10 years of the Great Cultural Revolution of China returned to the cities. This return has huge influence. However, this song is just close to this social reality. Therefore, it is widely spread and loved by numerous Chinese people.

With The Half Moon as an example, this pop song was written by Li Haiying, a famous word and music writer in China. The version sang by Liu Huan, a famous pop singer at the mainland, is known by the most people. The reason for this pop song's becoming a classical song mainly lies on its successful integration of the essence of pop music into classical and national music elements, so 
as to achieve the combination of art and popularity. This pop song is a piece of representative work for the present popular songs at the mainland. At the same time, it also had wide influence in the world. The words of The Half Moon in the verse: in the distant night sky, there is a half moon. Below the moon, there is an arched bridge. Besides the bridge, there is a curved boat. The dream girl in the childhood is sitting in the boat. The girl is singing an old song while paddling the boat. Her singing blows to my face with the wind. Tears are falling down my face, just like winding river water flowing into my heart. The words of this song are quite vivid in the verse part, making the audiences as if placing them into the beautiful Yangtze River delta. Although the words of this song are of artistic aesthetics, it is by no means separated from the real life. Instead, it is quite close to the real life. This is also very obvious in the chorus: my heart is full of disconsolation, not for the half moon, but for the present village. The old song is still singing. Oh, the moon in my hometown, your depression penetrates into my chest. We can obviously experience its realistic feeling of being close to life by using for reference the historical background of this classical song. At that time, China was still in the initial stage of the reform and opening up. As the reform and opening-up policy was just implemented, some rural areas were still laggard when compared with great economic development of big cities. However, this song just grasped this realistic feature, and reflected the reality on the basis of emotional expression, so as to obtain good realistic effects and artistic standards. Plus the wonderful singing by the singer, this song becomes a classical one in the history of pop music in Contemporary China.

\section{Combination of Direct Technique of Expression with Vivid Emotions}

One major feature of pop music lies on the direct technique of expression. This point is reflected in its straight expression of words and its simple and catchy melody. By virtue of delicate, profound and flexible emotion expression ways, pop songs are loved by many listeners. The melody of pop songs is gentle. Besides, most people are within the natural range of human voice. Therefore, pop songs can be accepted by the public, and then widely popularized. For traditional pop songs, it is mainly of $4 / 4$ beats. With the continuously enriched form and content of pop songs, 2/4, 3/4, 6/4 and other beats appeared gradually. Besides, pop songs are also good at the mixed use of beats. Plus the reverberation of other electronic music, pop songs bring forth a fresh experience in a different style for the listeners.

At the same time, the reason for why pop songs are accepted and loved by the masses is the treatment of its rhythm. As everyone knows, rhythm and melody are of the same importance for music. No matter for instrumental music or vocal music, the application of rhythm will influence the connotation expression of the whole work to a large extent. Chinese classical pop songs are featured by free and variable rhythm. Moreover, it is also wide in the application of segmenting rhythm and floating notes. Additionally, Chinese classical pop songs are also good at utilizing various kinds of value bar span syncope to reach a rhythmic state of music. Thus, it not only ensures the movement of the whole song but also makes its rhythm to be distinct.

With Sister Go Boldly Forward (Zhao Jiping) as an example, this song is an interlude of Red Sorghum, a piece of work created by the fifth-generation director Zhang Yimou. As a movie interlude, what it brings forth to the listeners is rough and heroic sense of musical beauty to the most direct. This song is one of master works for the organic combination between the direct technique of expression and vivid emotions. Therefore, it can become a piece of classical work in the heart of one generation.

With A Torch in Winter (Fei Xiang) as an example, this song is a typical pop music work with the rhythm of dance music as the trunk. The application of the rhythm of dance music not only makes the whole song to be more expressive but also provides a wider platform for its communication and popularity. Many Chinese classical pop songs absorbed the dance music elements of jazz, disco, rumba, tango and others alike. The application of these elements makes musical works to be more colorful and more three-dimensional.

In the 21 st century, Chinese classical pop music gradually introduced some new music elements of foreign pop music based on the absorption of such dance music as jazz, disco, rumba and tango, 
such as RNB and Hip-Hop. The application of these pop elements makes the Chinese pop music to be more international. With his variable styles of singing and excellent singing, Jay Chou, a new singer in Taiwan, attracted hundreds of millions of young people. Besides, Jay Chou also properly applied the elements of the Chinese style into pop music, so as to reach the combination of the art and expression features of pop music. With his status of the king of pop music in the new period in Asia, Jay Chou received wide attention from the whole Asia and even the world. His classical pop music works are numerous, with extremely profound influence in both Taiwan and Hong Kong.

In short, Chinese classical pop music has overwhelming influence in terms of rhythm. Moreover, it also properly eradicated the mechanical movement of traditional musical form, bringing forth a rhythmic, continuous and flexible dynamic feature. Thus, Chinese classical pop music not only provides more choices for music appreciation for the listeners but also expands the expressive force of the whole Chinese music.

\section{The Native Traditional Culture and Absorb Foreign Pop Elements}

As everyone knows, the performance of singer decides the development of the whole song and the demonstration of artistic effects to a large extent for pop music. Therefore, the development of Chinese classical pop songs cannot be separated from a group of excellent pop singers. Correspondingly, Chinese classical pop songs fully used for reference excellent pop music works in foreign countries based on excellent Chinese culture, especially for pop songs in Hong Kong and Taiwan.

With the gradual implementation of the reform and opening-up policy in China in the 1980s, foreign pop culture also quickly entered Chinese society. Certainly, these pop cultures include foreign pop music. Chinese pop music gradually developed based on excellent native culture and by fully absorbing foreign pop elements. Therefore, many Chinese classical pop songs have distinctive features of foreign pop culture.

Mentioning the influence of excellent foreign pop music on Chinese pop music, we have to mention about the influence of Japanese pop music on China, especially on Hong Kong and Taiwan. The influence of Japanese pop music on pop music in Hong Kong and Taiwan not only lies on the arrangement of melody but also on the control of the whole rhythm. Besides, many excellent Japanese love songs and motivational songs were recomposed and covered with Cantonese words. Similarly, these songs also remarkably influence the development of pop music in Hong Kong and even the mainland.

With gradually deepened cultural exchange among various countries after the 1980s, a group of excellent video works and music works also gradually entered China. Japanese and American pop culture had wide influence first in Hong Kong and Taiwan. Then, Japanese and American pop culture was gradually spread to the mainland, profoundly influencing the development of Chinese pop music.

\section{Excellent Songs Emerge Endlessly, with Extremely Distinct Territoriality}

Just as mentioned above, whether pop music is classical or not is sourced from the annotation by the singers to a large extent. Because of numerous pop artists like Elvis Presley and Michael Jackson, America can become a great power of pop music in the world. Just because of a group of excellent pop singers, Chinese classical pop music is recognized, accepted and loved by the masses.

Mentioning Chinese classical pop music, one name must appear in the brain of people. That is Deng Lijun. In the 1980s, her graceful and euphemistical singing entered the Chinese mainland with numerous tapes, thus creating a group of classical songs loved by the masses. Compared with traditional music, pop songs are featured by diversified techniques of expression. Breath, application of true and false sound and others are served as important ways of emotional expression of pop songs. By virtue of her graceful, delicate and soulful singing style, Deng Lijun not only created a batch of classical pop music works but also made huge contributions to the whole Chinese pop music. 
As everyone knows, China has a vast territory and a large population as well as a long history and bright and colorful national culture. Therefore, Chinese classical pop music is of extremely distinct regional art feature. Besides excellent foreign pop music and excellent music in Hong Kong and Taiwan in the 1980s, the Chinese Mainland also generated many classical pop music works. Northwest Wind is one of outstanding representative works.

In the northwest of China, there is vast land and profound accumulation of historic culture. Just because of this profound connotation of natural culture plus rock music gradually entering China in the late 1980s and the processing and performance of modern singing style by pop singers, a batch of widely known northwestern songs emerged. Among these songs, the most popular ones are My Passionately-beloved Hometown (Fan Linlin), Xintianyou (Hang Tianqi), Leave for the West (Hu Yue) and Mountain Gully (Na Ying).

Northwestern songs are lived and welcomed by the masses because of the desolate, bold and generous expression of art and natural and vivid singing style. Moreover, northwestern songs have unfailing expression of art. This expression of art is just sourced from the profound historical and cultural deposits. By virtue of soul-stirring, passionate, bold and generous features and plain expression of art, northwestern songs give incisive and vivid expression to desolate and dignified Loess Plateau. Artistic characteristics of northwestern songs lie on the unique integration of regional culture with pop elements, thus adding the artistic expression of pop culture based on the expression to excellent natural culture.

Although many years past away, these classical northwestern songs are still loved and sang by many fans. The artistic charm of northwestern songs just lies on the sufficient combination with the passionate times and the unique soul shock to the listeners. This unique soul shock not only forged northwestern songs but also gave new features to Chinese pop music.

\section{Conclusion}

To sum up, pop music was deemed as decadent music and secular culture within a period of time. However, it certainly will have greater influence in the later Chinese society by virtue of its vivid emotional expression and profound mass base. Chinese classical pop music is based on excellent national and traditional culture. At the same time, Chinese classical pop music also used for reference excellent pop culture in foreign countries. Media play an irreplaceable role. With the continuous changes in the public's aesthetic ways and the continuous development of influencing technologies, therefore, pop music surely will make continuous innovations and development on the present basis, so as to meet continuously improved spiritual and cultural demands of the masses.

\section{References}

[1] Zhong Bin, Analysis on Words of Several Classic Pop Songs in the $20^{\text {th }}$ Century in China [J], Shidai Wenxue, 2009 (20);

[2] Sun Aijun, Secularization and Popularity of Mass Culture [J], Tribune of Social Sciences, $2002(06)$;

[3] Tao Xin, Manual of Pop Music [M], Shanghai: Shanghai Music Publishing House, 1998 